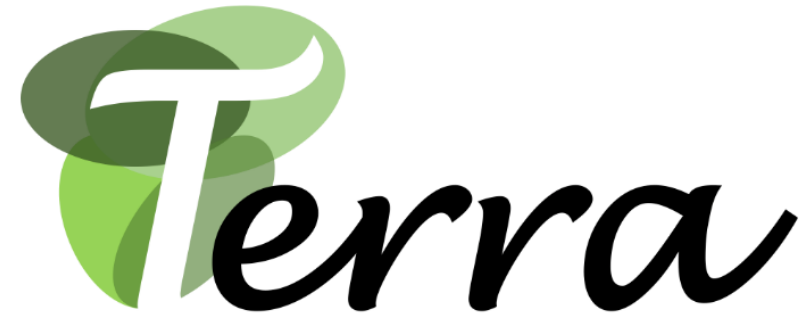

Revista de Desarrollo Local

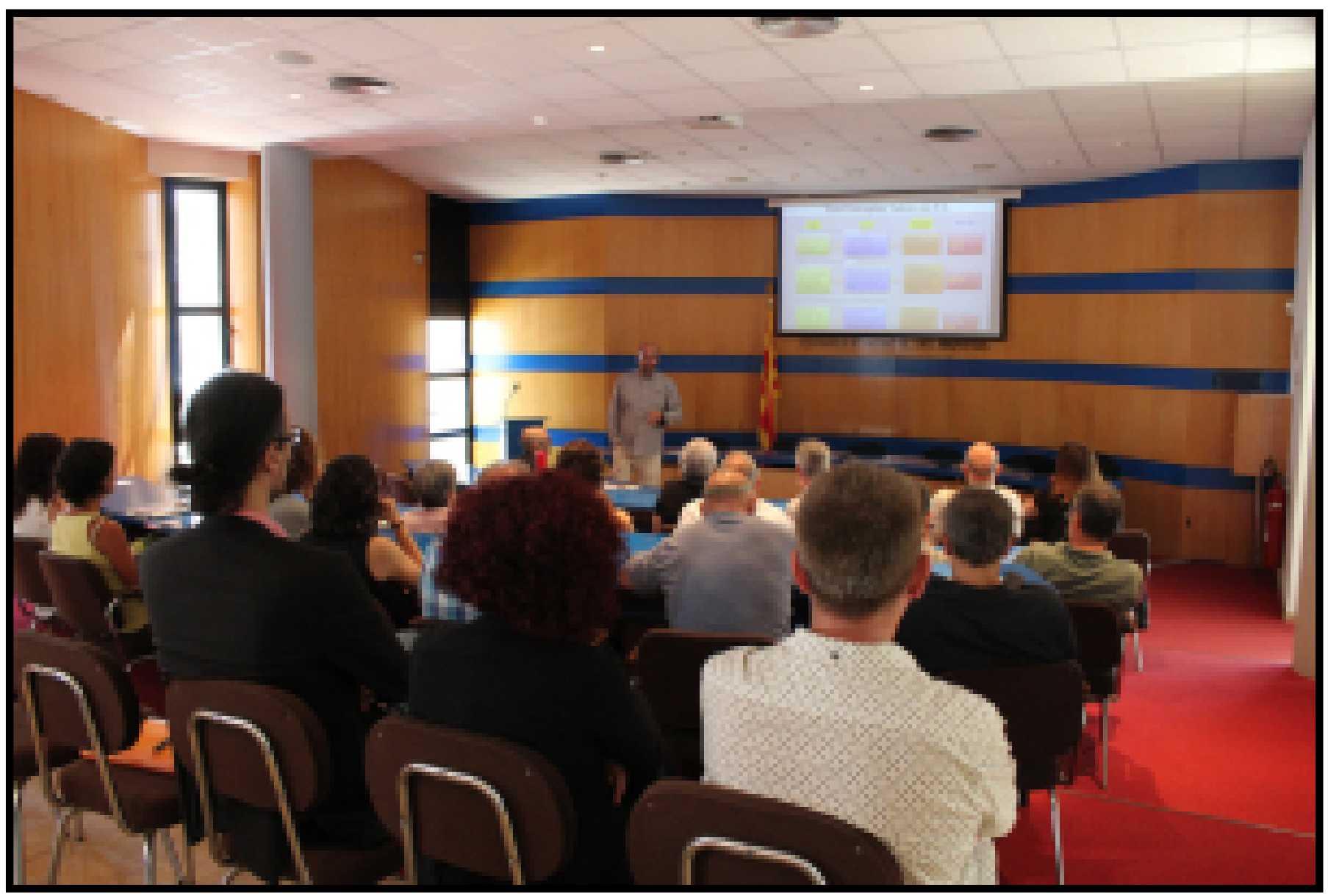

- Homenaje a Joan Noguera Tur -

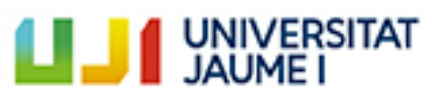

Institut Interuniversitari de Desenvolupament Local

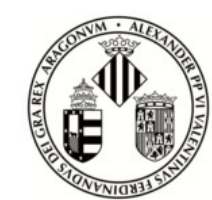

VNIVERSITAT

[B VALÈnCIA 
TERRA. Revista de Desarrollo Local e-ISSN: 2386-9968

Número 8 (2021), 784-790

DOI 10.7203/terra.8.21202

IIDL - Instituto Interuniversitario de Desarrollo Local

\title{
Reseña. Comunidades discriminadas y territorios rurales abandonados. Políticas públicas y derecho administrativo frente a la despoblación
}

\author{
Javier Iturrino-Guerrero \\ Prof. Asociado del Dpto. de Geografía de la Universidad de Valencia. Consultor \\ profesional \\ igueja@uv.es \\ https://orcid.org/0000-0002-0347-7387
}

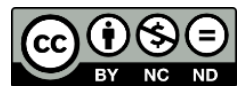

Esta obra se distribuye con la licencia Creative Commons

Reconocimiento-NoComercial-SinObraDerivada 4.0 Internacional 


\section{SECCIÓN RESEÑAS}

\section{Reseña. Comunidades discriminadas y territorios rurales abandonados. Políticas públicas y derecho administrativo frente a la despoblación}

Resumen: La obra "Comunidades discriminadas y territorios rurales abandonados. Políticas públicas y derecho administrativo frente a la despoblación" del joven jurista, investigador (FPU) del Departamento de Derecho Administrativo, Financiero y Procesal de la Facultad de Derecho de la Universidad de Salamanca, José Luis Domínguez Álvarez, supone una bocanada de aire fresco a los legos del derecho y la jurisprudencia. Una obra que desmenuza los terrones de las leyes, programas, instrumentos y herramientas enraizadas en el mundo rural, dando lugar al drama de la despoblación y el abandono. Sin embargo, esta aportación insta a las Administraciones Públicas a preparar el campo para plantar una nueva simiente que sea, verdaderamente, la búsqueda de la igualdad real y el equilibrio territorial evitando la sangría demográfica en el mundo rural.

Palabras clave: desarrollo rural sostenible, derecho administrativo, objetivos de desarrollo sostenible, desigualdades territoriales, vivienda, telecomunicaciones, igualdad de género.

Recibido: 22 de junio de 2021

Devuelto para revisión: -

Aceptado: 22 de junio de 2021

\section{Referencia / Citation:}

Iturrino-Guerrero, J. (2021). Reseña. Comunidades discriminadas y territorios rurales abandonados. Políticas públicas y derecho administrativo frente a la despoblación. TERRA. Revista de Desarrollo Local, (8), 784-790. DOI 10.7203/terra.8.21202 


\section{José Luis Domínguez Álvarez \\ COMUNIDADES DISCRIMINADAS Y TERRITORIOS RURALES \\ ABANDONADOS. POLÍTICAS PÚBLICAS Y DERECHO ADMINISTRATIVO FRENTE A LA DESPOBLACIÓN}

Pamplona (España), Aranzadi Thomson Reuters, 2021, 297 páginas

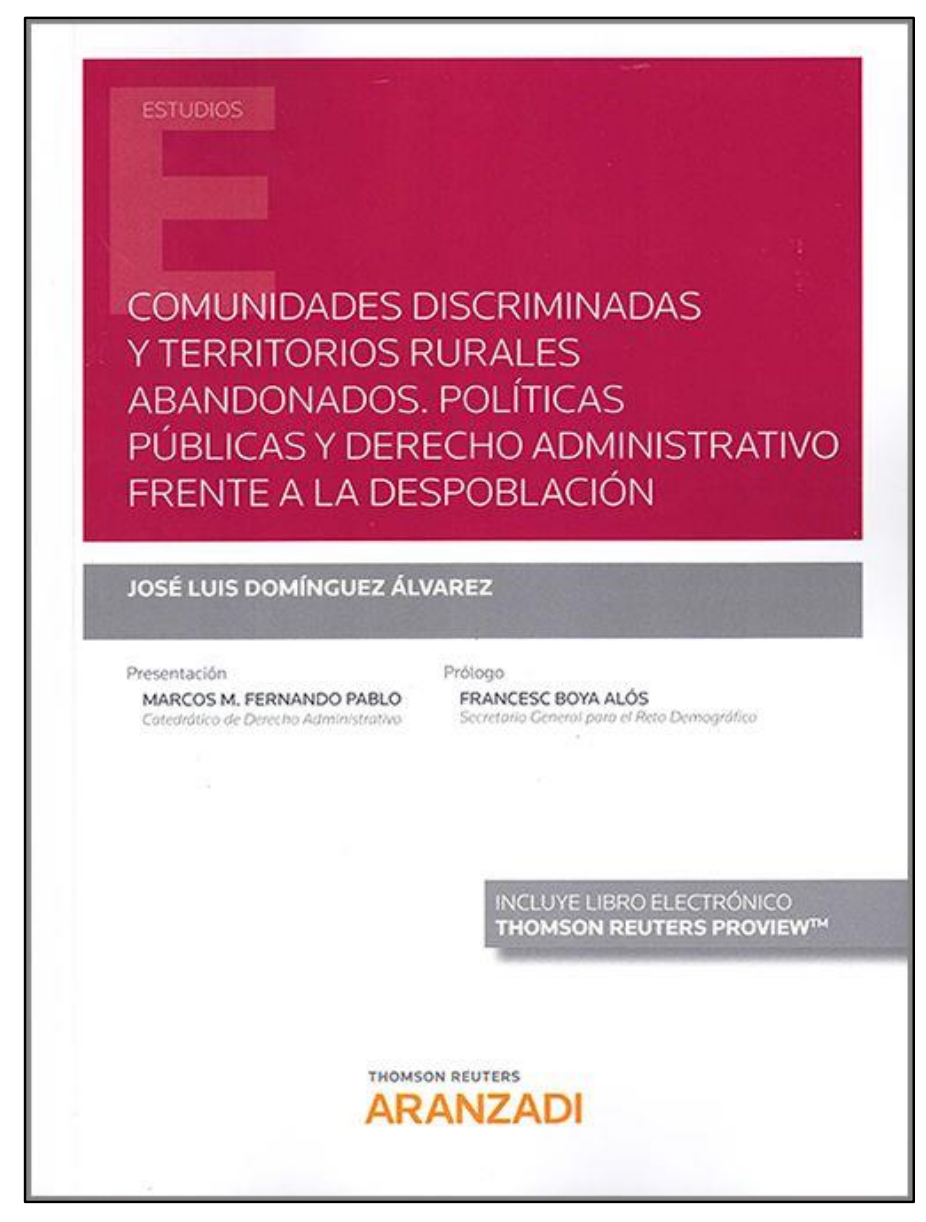

El libro, publicado en un momento en el que la demografía aparece de forma tozuda en los medios de comunicación, ya sea por los fenómenos de despoblación o de migraciones que están teniendo lugar, está prologado por Francesc Boya Alós, Secretario General para el Reto Demográfico y presentado por Marcos M. Fernando Pablo, catedrático de Derecho Administrativo de la Universidad de Salamanca, compañero de departamento del autor.

Esta publicación, tal como está redactada, sólo puede estar hecha por alguien portador del polvo y el sudor que la esencia del mundo rural ha dejado en sus genes y que circula por su sistema cardiovascular. José Luis Domínguez Álvarez, hijo del municipio Cerceda de la Sierra, "gato" de la Sierra de Francia (Salamanca), muestra sentido y sensibilidad al tratar las problemáticas que percuten y repercuten en el vaciamiento demográfico de los territorios rurales españoles.

Afronta, a través de la novena capitular del libro, cómo fue la génesis y evolución del abandono rural y las acciones innovadoras necesarias para evitar lo que denomina como "crónica de una muerte anunciada". Desmenuza a buen ritmo las particularidades de las leyes y normativas que afectan al mundo rural, especialmente las que inciden en el despoblamiento.

Siempre buscando la explicación que subyace en la normativa, en su inspiración y en el interés general que hay en las leyes, ordenanzas, programas y demás elementos regulatorios de diferente rango, ya sea desde instituciones como la Unión Europea, ya sea desde el ámbito del Estado o desde las competencias autonómicas y locales.

El autor, que a través de una escritura ágil y sencilla evita una lectura farragosa de un texto jurídico de estas características, aporta cifras, datos y explicaciones en su periplo por las leyes, estrategias y jurisprudencia que afectan al mundo rural, al tiempo que 
muestra una sensibilidad especial por los aspectos sociales que constriñen los conductos del ascenso de la sabia del desarrollo rural.

A su vez, puede señalarse que no deja títere con cabeza al mostrar los posibles culpables de ciertas situaciones que han lastrado y lastran de forma insistente el progreso de los territorios rurales españoles.

Además de los problemas ya sabidos, señala y analiza cuando menos desde la perspectiva del Derecho Administrativo, los desequilibrios de un sistema asentado en las desigualdades de acceso de la población rural a los servicios públicos esenciales como la educación, la sanidad, las nuevas tecnologías, la cultura...

A medida que uno va leyendo el texto, se sumerge en toda una serie de acontecimientos que han ido marcando el devenir del paisaje y paisanaje del mundo rural. Leyes, políticas, programas europeos, programas nacionales, programas autonómicos, fondos europeos para el desarrollo, grupos de acción... En definitiva, un complejo engranaje que, principalmente, es gobernado desde entornos urbanos que son los que deciden sobre los espacios rurales. Toda una compleja superestructura burocrática que aploma la capacidad de mejora y reequilibrio de unos territorios envejecidos demográficamente.

Tal como señala el autor, el incremento de las desigualdades entre las zonas urbanas y rurales en los entornos europeos, la despoblación y el abandono de territorios se ve catalizado por el atraso económico y social a que se ve sometido el mundo rural. Sin embargo, esta situación puede ser reversible, evitable y explica por qué y cómo se puede salir de esta indeseable situación.

El viaje, al que nos conduce este cicerone transcurre por tierras otrora demográficamente fértiles, precisa de alforjas numantinas al pasar por caminos escabrosos en los que se hace necesario el acceso a recursos esenciales como la educación y la cultura de calidad; evitando que un acceso por parte de la población residente en estos espacios, costoso, ineficiente e ineficaz sea detonante de la pérdida de más efectivos demográficos que saldrán huyendo hacia los entornos urbanos.

Además de la carencia de acceso a la oferta educativa y cultural de calidad sin un incremento de costes para los usuarios que habitan en las zonas rurales, indica otra importante problemática existente como es la sanidad rural. Menciona brevemente, de forma didáctica y sin complicaciones para el lector, cómo se organizan las áreas de salud, las zonas básicas de salud y cuáles son los criterios básicos que marcan ésta organización. Y dentro de lo que puede considerarse como antesala a la búsqueda de soluciones, avisa sobre que la sanidad rural se encuentra seriamente amenazada en determinadas áreas geográficas de nuestro país.

Dentro de las desigualdades de acceso de la población rural a los servicios públicos esenciales también escribe sobre los servicios de transporte y la dotación de infraestructuras para garantizar la custodia del territorio. Y avanza cómo la regeneración urbana puede ser un buen instrumento para combatir la crisis de la vivienda en la España rural. Sí, la vivienda, es además de un bien de mercado un bien social y, una vez más, un elemento clave para asentar familias en el territorio.

José Luis Domínguez Álvarez, instruye sobre el espíritu de la Ley de Desarrollo Sostenible del Medio Rural sobre la necesidad de facilitar el acceso a la vivienda en el medio rural y, al tiempo, muestra cómo la crisis sociosanitaria provocada por la COVID19 ha dificultado aún más el acceso a la misma y a la emancipación de jóvenes en entornos rurales. También informa sobre el fracaso de las estrategias implementadas hasta la fecha que permitan mejorar la oferta y calidad de las viviendas en el mundo rural y como es 
perentorio el incremento de vivienda de protección pública para, especialmente, grupos de edades jóvenes que desean vivir en su entorno.

Han pasado ya tres décadas desde que Tim Berners-Lee y Robert Cailliau, mientras trabajaban en la Organización Europea para la Investigación Nuclear (CERN), realizaran la propuesta formal de la web que fue la génesis de Internet y del mundo actual, un mundo que ya no se puede concebir sin Internet. La desconexión digital de las áreas rurales españolas es, como indica el autor, otro de los grandes desequilibrios en la prestación de servicios básicos a la población ligados a la falta de racionalidad del sistema que está, básicamente, organizado desde la "lógica" economicista.

El acceso a los nuevos servicios de telecomunicaciones es de vital importancia para evitar el tradicional aislamiento de los espacios rurales y para conseguir la cohesión económica y social y la vertebración territorial. Para ello, el autor propone desde una perspectiva holística la articulación de una "Estrategia Nacional frente al Reto Demográfico" que hagan de las telecomunicaciones un servicio de interés general.

Por otra parte, el compromiso que se aprecia con el feminismo, con el "alma de los pueblos" en el autor es de agradecer. Las explicaciones de la situación de la mujer en el medio rural, la demografía, el empleo y las situaciones de violencia hacia las mujeres son bloques temáticos que no soslaya para poder proponer acciones que mitiguen la desigualdad de género $\mathrm{y}$, en definitiva, se enderece el camino para alcanzar la ansiada igualdad real entre mujeres y hombres como "(...) uno de los principales y más urgentes retos a abordar por parte de las diferentes Administraciones públicas".

La Adenda 2030 y los Objetivos de Desarrollo Sostenible (ODS) tienen cabida en el capítulo VI de la publicación, como una nueva oportunidad para promover el desarrollo sostenible en los entornos rurales. En este apartado, desmiembra el articulado y señala a los actores implicados, sin olvidarse de las Entidades locales, que deben impulsar el desarrollo sostenible en las áreas despobladas.

La complejidad estructural de la Administración pública no es óbice para que el autor sostenga que son el municipalismo y la propia autonomía local el sistema radicular del árbol del renacimiento rural, del resurgir de la ruralidad, de la autoestima de las áreas despobladas. Sin embargo, para empoderar a la Administración local, la que está más próxima a la ciudadanía, la encargada de satisfacer sus intereses generales y mejorar su calidad de vida, se hace preciso mejorar su financiación y articular mecanismos de control financiero y presupuestario más sencillos. Son, no nos olvidemos, las Entidades locales las encargadas en última instancia de prestar servicios esenciales a la población en las áreas rurales despobladas y, por tanto, la mejora de la financiación es una de las piedras angulares de la fijación de la población en los entornos rurales.

La publicación en 2013 de la Ley de Racionalización y Sostenibilidad de la Administración local (LRSAL) es explicada por el autor, señalando su esencia y sus ambiciosos objetivos para evitar el abandono institucional rural, la clarificación de las competencias municipales soslayando las duplicidades administrativas y, en definitiva, buscando la racionalización de la Administración local; desde principios de eficiencia, estabilidad y sostenibilidad financiera y presupuestaria. Otra cosa será que se alcancen los objetivos y la esencia de la ley; para ello será necesario, entre otras acciones mencionadas, la reformulación de los padrones municipales en favor del incremento de la financiación de los pequeños municipios.

A su vez, el autor de esta publicación, sostiene y explica que hay que promulgar leyes necesarias y específicas que se adapten a las vicisitudes del medio rural español, para 
evitar que la sobrerregulación ralentice con su ineficiencia el desarrollo local de espacios y territorios poco poblados y despoblados. Un capítulo de vital importancia ya que supone el fomento de leyes y normas que simplifiquen la complejidad de la estructura organizativa del Estado en las áreas rurales y que faciliten y catalicen el emprendimiento y la dinamización de sus economías.

Por último, José Luis Domínguez Álvarez, tal vez como buen salmantino conocedor de las problemáticas de las tierras de frontera, de límite entre territorios, elabora un capítulo específico sobre el desarrollo rural sostenible transfronterizo. Marcando el valor de la cooperación y colaboración interterritorial en espacios vecinos que, por su condición de límite, sufren más que otros. Programas europeos como INTERREG han sido piezas clave para articular proyectos y propuestas en favor del desarrollo rural, pero hay mucho camino por recorrer en esta carrera de fondo campo a través de la España vaciada.

En definitiva, esta publicación es un compendio muy recomendable como "libro de cabecera" para cualquier alcalde, alcaldesa, alcaldable, responsable de concejalía, técnico y demás interesados en el mundo rural pues dispondrán de la esencia y una clara explicación de las leyes, ordenanzas, jurisprudencia, planes, estrategias... que les afectan desde una perspectiva humanista del Derecho Administrativo. ¡Todo un acierto!

Javier Iturrino-Guerrero

Licenciado en Geografía (Universidad de Valencia), Licenciado en Bellas Artes (Universidad Politécnica de Valencia) y Máster Oficial Universitario en Técnicas para la Gestión del Medio Ambiente y del Territorio (Universidad de Valencia). Profesor Asociado del Área de Geografía Humana del Dpto. de Geografía de la Universidad de Valencia (España). Consultor profesional 